${ }^{1}$ Dr. Shafia Khatun Nayan Assistant Professor Dept. of Community Medicine Northern International Medical College, Dhaka

2

${ }^{2}$ Dr. Nasreen Begum

Assistant Professor

${ }^{3}$ Dr. Mumtaz Rahman Abid

Associate Professor

${ }^{4}$ Dr. Sanjida Rahman Lecturer

${ }^{5}$ Dr. Ahsanul Kabir Rajib

Lecturer

${ }^{6}$ Dr. Nashid Farzana Lecturer

${ }^{7}$ Dr. MST. Laizuman Nahar Lecturer, Pathology Ad-din Women's Medical College

\section{$2,3,4,5,6$}

Dept. of Community Medicine Northern International Medical College, Dhaka

\section{Correspondence}

Dr. Shafia Khatun Nayan

Assistant Professor

Dept. of Community Medicine

Northern International Medical College

E-mail : shafiag40@gmail.com

\title{
Utilization of Postnatal Care Services among the Rural Women in Bangladesh
}

\author{
S K Nayan ${ }^{1}$, N Begum² ${ }^{2}$ M R Abid ${ }^{3}$, S Rahman ${ }^{4}$, A K Rajib ${ }^{5}$, N Farzana ${ }^{6}$, M L Nahar ${ }^{7}$
}

Abstract

Background : Low utilization of routine postnatal care (PNC) is an important determinant of high maternal and neonatal mortality in Bangladesh.

Objective : To determine the utilization of post-natal care services among the rural women in a selected area in Bangladesh.

Methodology : During October 2015 to March 2016 a descriptive, cross-sectional study was carried out among 200 married women of reproductive age who had a live baby below 5years of age. Sample was selected purposively from village Islampur in Dhamrai Upzilla under Dhaka district. After taking informed consent data were collected by face to face interview using structured questionnaire.

Results : The study revealed that $73.50 \%$ of the respondents utilized PNC services among them $55.10 \%$ took PNC for less than 3 times and $28.57 \%$ took PNC for more than 3 times during postnatal period. Most of them $86 \%$ were house wife; age between $25-30$ years. About $35 \%$ respondents were educated up to secondary level and $31.5 \%$ were from middle economic group. In this study $79.50 \%$ respondents received Antenatal care and advice for Post-Natal Care (PNC) Source of information for PNC was $32.5 \%$ from health workers. Fifty nine percent respondents took PNC on combined decision of husband and wife. A significant number of respondents $61.91 \%$ received postnatal care at Upazilla Health Complex. Most of the respondents $73.47 \%$ found health care provider available on duty and good behavior were found by $72.11 \%$ respondents. Among respondents $62.59 \%$ attended Health Centre by walking. Only $59.86 \%$ respondents got free PNC service. Regarding importance of PNC $67.5 \%$ believed for healthy mother and $12.5 \%$ for healthy baby.

Conclusions: Post Natal Care service utilization was satisfactory $(73.50 \%)$ in the study area which is higher than the national figure $(36 \%)$. The findings of the study clearly showed that female education, monthly household income, antenatal care utilization, distance of health center turned out important factors in determining the postpartum care utilization among the mothers. Availability and interaction with health care providers also affected the postpartum care utilization in the study population.

Key Words : Post-natal period, Post-natal care, Post-natal visit, post-natal advice.

Northern International Medical College Journal Vol. 8 No. 02 January 2017, Page 208-212

\section{Introduction}

The postpartum period, or puerperium, starts about an hour after the delivery of the placenta and includes the following six weeks. Postpartum care should include the prevention and early detection and treatment of complications and disease, the provision of advice and services on breastfeeding, birth spacing, immunization and maternal nutrition. ${ }^{1}$ Every year, nearly half a million women and girls needlessly die as a result of complications during pregnancy, child birth or at six weeks following delivery. Almost $99 \%$ of these deaths occur in developing countries. Bangladesh is committed to achieving the Millennium Development Goal 5 (MDG-5) that specifies a $75 \%$ reduction in the maternal mortality ratio between 1990 and $2015 .^{2}$

Pregnancy and childbirth are special events in a women's life. But during this period they are more vulnerable to disease and death. Many women who give birth in facilities are discharged within hours after childbirth, without any instructions about where they can obtain further care or support. ${ }^{3}$ The World Health Organization (WHO) guidelines 
postnatal visits within six to 12 hours after birth, three to six days, six weeks, and at six months. ${ }^{4}$

The proportion of women receiving postnatal check-up from a medically trained provider within two days of giving birth depend on women's age, birth order, urban-rural residence, education, and wealth quintile. Due to many socio-economic and cultural reasons, such as the distance to travel and the cost of attending and so on, most rural mothers avoid going facilities and give birth at home. For this, women are being deprived of government health services that results in serious maternal and neonatal death. ${ }^{5}$

Report focuses that around two-thirds of all deliveries occur at home with unskilled birth attendants. It is found that only $21 \%$ of mothers and $22 \%$ of neonates receive postnatal care (PNC) from a medically trained provider within 42 days after birth in Bangladesh. ${ }^{6}$ It is suggested that in most developing countries like Bangladesh, postnatal care may be implemented if provided through home visits, because due to geographic, financial, and cultural barriers it gets really tough to provide facilities outside the home during the early postnatal period. ${ }^{7}$ Post natal care for mother has conventionally focused on routine observation and examination of vaginal blood loss, uterine involution, blood pressure and body temperature counseling on breastfeeding; and advice on nutrition during breastfeeding, newborn care practices, and family planning and referral for complications. ${ }^{8}$ Early postnatal care for all newborns is a must. This care should include immediate and exclusive breastfeeding, warming of the infant, hygienic care of the umbilical cord, and timely identification of danger signs with referral and treatment. Since the majority of newborn deaths occur among low birth weight (LBW) babies, extra effort is needed for LBW newborns to ensure their care. ${ }^{9}$ Studies have shown that access to effective antenatal care can lead to better utilization of delivery care, postnatal care and treatment and management of pregnancy, delivery and postnatal complications. ${ }^{10}$

In Bangladesh a postnatal checkup from a medically trained provider within two days of delivery has increased from $20 \%$ in 2007 to $27 \%$ in 2011 , to the current level of $36 \%$ for mothers. For children, a postnatal checkup from a medically trained provider within the first two days has increased from $20 \%$ in 2014 to the current level of 32\%. The HPNSDP 2011-2016 sets a target of $50 \%$ of women receiving at least one postnatal visit by a medically trained provider within 48 hours of birth by $2016 .{ }^{11}$

The present study was conducted to assess the socio demographic character of women utilizing post natal care services, their knowledge on post natal care and related factors influencing utilization of health services in postnatal period.

\section{Material and methods}

This cross-sectional type of descriptive study was carried out between October 2015 and April 2016. A total 200 married women of reproductive age who had one living child below five year were selected purposively from village Islampur in Dhamrai Upazila under Dhaka district. After taking informed consent, data were collected by face to face interview, using a pretested questionnaire. Data was entered into SPSS version 16.0 and analyzed by the researchers.

\section{Results}

Socio demographic characteristics showed that majority (50.5\%) of the respondents were 25-30 years of age. Among the respondents (35\%) completed secondary education. Majority $(86.00 \%)$ of the respondents was housewife (Table 1$)$.

Table I : Socio demographic profile of respondents (no.200)

Age of respondents
Age group

Below 18

$18-24$

25-30

31-36

$37-42$

Above 43

Educational status of the respondents

\section{Educational status}

Illiterate

Can sign

Primary education

Secondary education

SSC or equivalent

HSC or equivalent

Graduate and above

Occupation of the respondents

\section{Occupation}

Housewife

Service holder

Garments worker

Business

Day labour

House maid

Others

$\begin{array}{cc}\text { Frequency } & \text { Percentage } \\ 11 & 5.5 \% \\ 63 & 31.50 \% \\ 101 & 50.50 \% \\ 18 & 9.00 \% \\ 4 & 2.00 \% \\ 3 & 1.50 \%\end{array}$

$\begin{array}{cc}\text { Frequency } & \text { Percentage } \\ 5 & 2.50 \% \\ 19 & 9.50 \% \\ 56 & 28.00 \% \\ 70 & 35.00 \% \\ 21 & 10.50 \% \\ 22 & 11.00 \% \\ 7 & 3.50 \%\end{array}$

$\begin{array}{cc}\text { Frequency } & \text { Percentage } \\ 172 & 86.00 \% \\ 15 & 7.50 \% \\ 6 & 3.00 \% \\ 0 & 0.00 \% \\ 3 & 1.50 \% \\ 3 & 1.50 \% \\ 1 & 0.50 \%\end{array}$

Economical status revealed that monthly income was between Tk. 10,001-15,000, among $31.5 \%$ respondents and only $12.5 \%$ income was Tk. above 20,000. (Figure 1) 


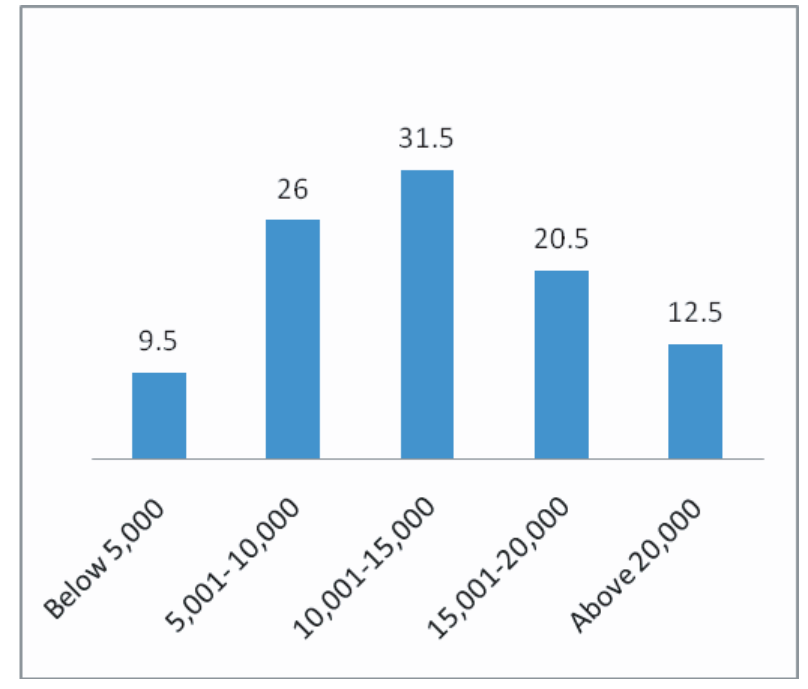

Fig 1 : Monthly family income

\section{Socio cultural information}

Study result showed that $79.50 \%$ respondents took Ante-natal care also received advice for Post- natal care and $20.50 \%$ respondents never took Ante-natal care and not received advice for post-natal care during ante-natal visit. (Fig 2)

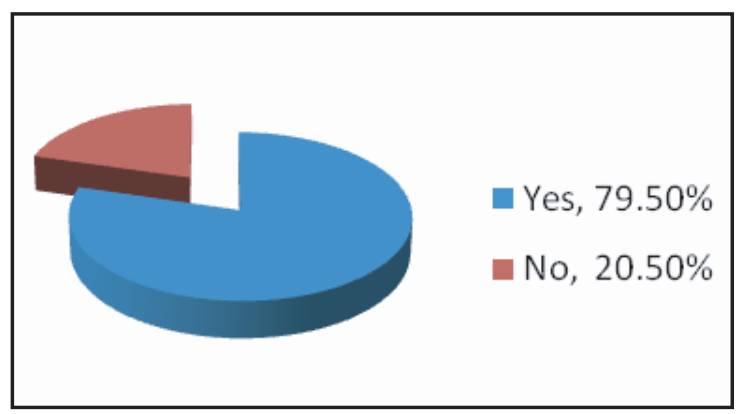

Fig 2 : Received Ante-Natal Care (ANC) and advice for PNC

The result showed that, $58.5 \%$ of respondent took post-natal care on husband and wife's combined decision and 19.05\% according to husband decision. (Fig 3)

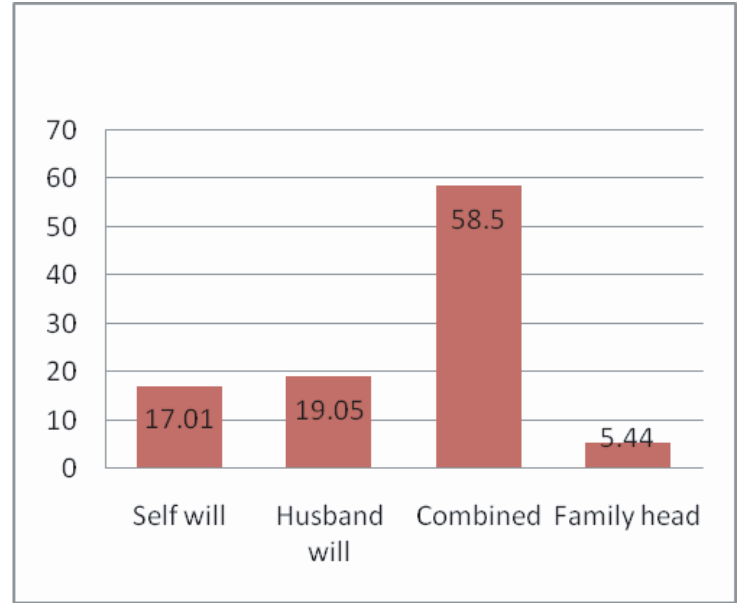

Fig 3 : Decision for taking post-natal care (PNC)
It is evident form table that, $61.91 \%$ of respondents were received post-natal care service at UHC, $29.25 \%$ of respondents were received post-natal care service at clinic, $5.44 \%$ of respondents received post-natal care service at home. (Table IV)

Table III : Place of receiving post-natal care services

$\begin{array}{lcc}\text { Place } & \text { Frequency } & \text { Percentage } \\ \text { Home } & 8 & 5.44 \% \\ \text { UHC } & 90 & 61.91 \% \\ \text { Clinic } & 43 & 29.25 \% \\ \text { NGO } & 4 & 2.72 \% \\ \text { Others } & 2 & 0.68 \% \\ \text { Total } & 147 & 100 \%\end{array}$

Study result revealed that $67.5 \%$ had idea that PNC important for having a healthy mother after delivery, $12.5 \%$ thought PNC important for a healthy baby and $20 \%$ respondents don't know about its importance (Figure 4)

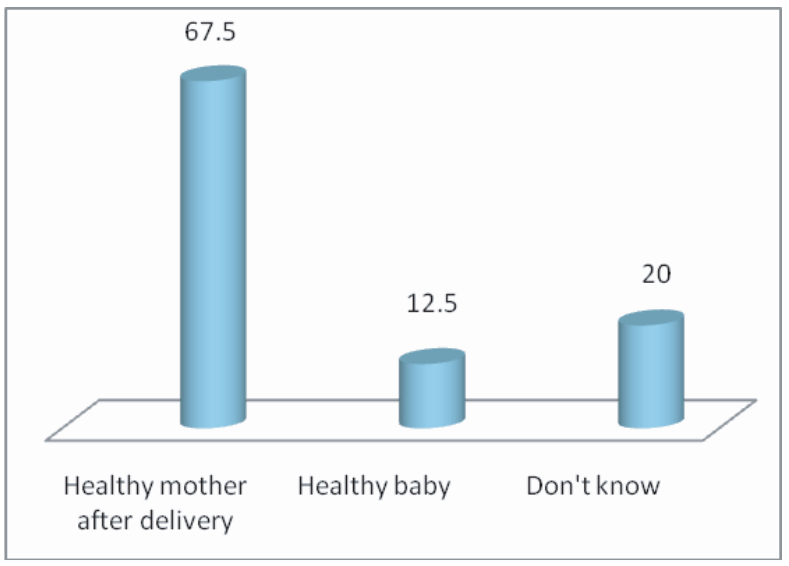

Fig 4 : Idea on importance of PNC service

\section{Information's regarding PNC service utilization.}

It is evident from figure that $73.5 \%$ respondents took post-natal care during their last pregnancy and $26.5 \%$ never took postnatal care during last pregnancy Fig 5

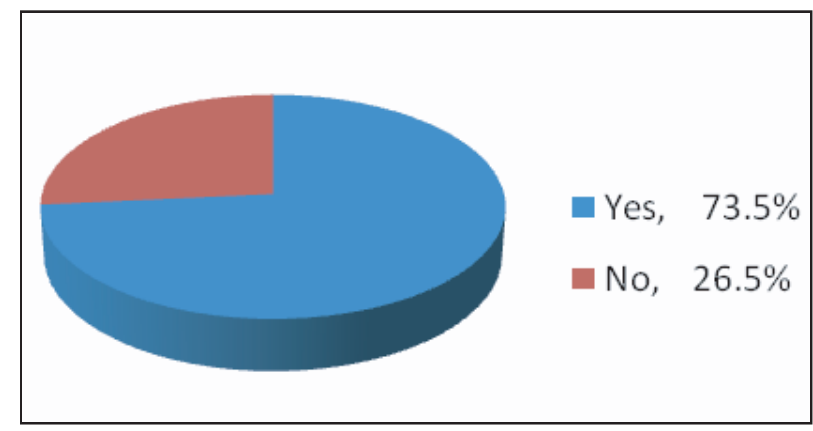

Fig 5 : Received post natal care during last pregnancy

Regarding number of receiving PNC service result showed that $55.1 \%$ had receiving post-natal care services less than 3 times, 
$16.33 \%$ had receiving post-natal care services 3 times and $28.57 \%$ had receiving post-natal care services more than 3 times. (Fig 6)

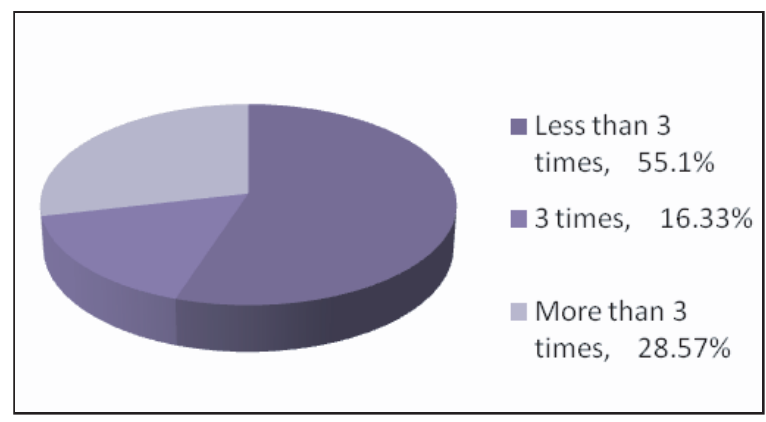

Fig 6 : Number of receiving post-natal care (PNC) service

Regarding PNC service result showed that $73.47 \%$ of service provider was available and $26.53 \%$ of the respondents got very good behavior, $72.11 \%$ got good behavior from the health care provider. PNC service received by $59.86 \%$ respondents from free of cost and $62.59 \%$ respondents had health care centre where they could go by foot and $37.41 \%$ respondents had to go there by vehicle (Table V).

Table IV : PNC service utilization by respondents

$\begin{array}{lcc}\begin{array}{l}\text { Availability of the health care provider } \\ \text { Available }\end{array} & \text { Frequency } & \text { Percentage } \\ \text { Yes } & 108 & 73.47 \% \\ \text { No } & 39 & 26.53 \% \\ \text { Behavior of the health care provider } & & \\ \text { Behavior } & \text { Frequency } & \text { Percentage } \\ \text { Very good } & 39 & 26.53 \% \\ \text { Good } & 106 & 72.11 \% \\ \text { Ba } & 2 & 1.36 \%\end{array}$

Pay for receiving the post-natal care service

\begin{tabular}{lcc} 
Payment & Frequency & Percentage \\
Free of cost & 88 & $59.86 \%$ \\
Less than 50 taka & 24 & $16.33 \%$ \\
More than 50 taka & 35 & $23.82 \%$ \\
\multicolumn{2}{l}{ Distance of health care centre from the residence of respondents } \\
Distance & Frequency & Percentage \\
Walking distance & 55 & $37.41 \%$ \\
By vehicle & 92 & $62.59 \%$
\end{tabular}

Discussion

This cross sectional study was designed to determine the utilization of postnatal care services in a selected rural community. It was observed that a significant proportion of the study participants were young aged women between 25-30 years $(50.50 \%)$ and $19-24$ years $(31.50 \%)$, here younger women seek PNC more than older women. A study in Pakistan by AsmaYunus et all observed that younger women of age 15-29 are more likely to who utilized postnatal care service which is consistent with our result. ${ }^{12}$ The educational status of women reflected that $35 \%$ of the respondents' were educated up to secondary level. A significant relationship between mothers education and utilization of postpartum care services was found Kabuya Aminahin at Uganda. ${ }^{13}$

In our study $86 \%$ respondents were house wife and (35.5\%) from lower income group attended for PNC more than higher income group (12.5\%). In a study in rural India revealed similar result that most of the women attended for post-natal Care were from lower economic class. ${ }^{14}$ Opposite picture was found by AsmaYunus et al that women of higher income group were more likely to use postnatal care services as compared to the lower income group in urban settlement of Pakistan. ${ }^{12}$

Socio cultural information revealed that $79.5 \%$ respondents took Ante-Natal Care (ANC) and received advice for Post natal care (PNC) and 20.5\% respondents never took Ante-natal care (ANC). The report from the 2008 NDHS (Nigeria Demographic and Health Survey) showed that the women who received antenatal care were more likely to go for postnatal checkup than women who received no antenatal care. ${ }^{15}$

There is a culture of staying home after delivery and prohibition for a outsider to take care newly delivered mother ${ }^{16}$ but the scenario was different that $58.5 \%$ respondents took post-natal care on combined decision of wife and husband and $61.91 \%$ of respondents received post-natal care service at Upzila Health Complex (UHC).

People may invest less in health because of lack of information, low parental education, wide spread poverty and inequality, cultural influence, low public commitment to health education and general education. ${ }^{17}$ Our study results showed $67.5 \%$ respondents had idea that PNC important for having a healthy mother after delivery, $12.5 \%$ thought PNC important for a healthy baby and so for $73.50 \%$ of the participants attended postnatal services. This is very low compared with the nearly $90 \%$ uptake of postnatal services reported in developed countries. ${ }^{18}$ More than half of the respondent $62.59 \%$ received post natal care from doctor. Similar picture was found in a study conducted in a rural area of Pakistan. ${ }^{12}$

Availability, behavior of health care provider and cost of accessing care (travel cost, service fees, equipment cost) are important determinants of whether to seek care. Our study revealed that health care provider was available for $73.4 \%$ 
respondents and $72.11 \%$ of respondents got good behavior but the opposite scenario was found in study in southern Nigeria ${ }^{19}$ and in Zimbabwe. ${ }^{20}$ Muchabaiwa, et al. explained that poor attitude of health care providers towards women contributes to low utilization of PNC services in Zimbabwe. In the current study $59.86 \%$ respondents got free PNC, $16.33 \%$ respondents needed less than $50 \mathrm{Tk}$ and $23.82 \%$ respondents needed more than 50 Tk for PNC. In a study in Pakistan also support this finding. 12

Women may find it difficult to travel long distance for taking postnatal care in rural areas especially when the condition of the roads is poor. In our study among those who attended PNC, $62.59 \%$ respondents had health care within walking distance and $37.41 \%$ respondents had to go there by vehicle. This reflects that rural women were conscious and knew the benefit of PNC and they reached health centre by foot or by vehicle. The result of this study is consistent with the study in the rural Guatemala. ${ }^{21}$ In Ethiopia ${ }^{22}$ the most frequent reasons for not obtaining PNC was long distance to provider.

\section{Conclusions}

In our study area mother were found educated, though from middle and lower income class they were conscious about Post Natal care of their own and newly delivered baby. Utilization of PNC service was higher (73.50\%) than National figure (36\%) but lower than the developed countries (90\%). Availability and accessibility of PNC services, promoting information, education and communication in the community is recommended to increase effective and sustain utilization of post-natal care service

\section{References}

1. Safe Motherhood. In: Postpartum Care of Mother and Newborn: a practical guide. Maternal and newborn health: Safe motherhood unit Division of reproductive support. WHO. Geneva 1998. Available from URL: http://www.who.int/maternal_child_adolescent/document/who- rst-msm983/en/

2. United Nations Millennium Development Goal. Available from URL: www.on.org/millenniumgoals

3. WHO Technical Consultation on Postpartum and postnatal care. Department of Making. Pregnancy safer. World Health Organization. Available from URL: http://whqlibdoc. who .int/hq/2010/WHO-MPS-10.03 eng.pdf

4. Promoting Effective Perinatal Care: Essential Antenatal, Perinatal and Postpartum Care.Training module .WHO 2002. Available from URL: http://www.euro.who.int/data/assets/pdf file/0013/131521/E79235.pdf

5. World health organization. Making pregnancy safer. Millennium Development goal 5. 2008. Available from URL: http://www.who.int/making pregnancy safer/topics/mdg/index.ht
6. Winch, P. J., M. A. Alam, et al. (2005). Local understandings of vulnerability and protection during the neonatal period in Sylhet district, Bangladesh: a qualitative study. The Lancet366 (9484): 8.

7. Syed, U., S. Asiruddin, et al. (2006).Immediate and early postnatal care for mothers and newborns in rural Bangladesh. Journal of Health, Population and Nutrition 24(4): 11 Available at http://www.ncbi.nlm.nih.gov/pmc/articles/ PMC3001155/

8. Koblinsky, M., Anwar, I., Mridha, M.K., Chowdhury, M.E., Botlero, R. (2008). Reducing Maternal Mortality and Improving Maternal Health: Bangladesh and MDG 5 J Health PopulNutr. 26(3): 280-294.

9. World Health Organization (1998).Postpartum care of the mother and newborn: a practical guide. Geneva. Available at www.who.int/ maternal_child_adolescent/.../who_rht.../index.html, accessed on $15 / 12 / 2016$

10. WHO-UNICEF Joint Statement on Home Visits for Newborn Care: Maternal, newborn, child and adolescent health. World Health Organization. Available from: URL:http://www.who.int/maternal_child_adolescent/topics/newborn/ postnatal_care/en/index.html

11. Ministry of Health and Family Welfare (MOHFW), 2001.Bangladesh National Strategy for Maternal Health. Dhaka, Bangladesh.

12. AsmaYunus, SaroshIqbal et al. Determinants of Postnatal Care Services Utilization in Pakistan- Insights from Pakistan Demographic and Health Survey (PDHS) 2006-07 Middle-East Journal of Scientific Research 18 (10): 1440-1447, 2013 ISSN 1990-9233 (C) IDOSI Publications, 2013 DOI: 10.5829/idosi.mejsr.2013.18.10.12418

13. Aminah K. Factors determining utilization of postpartum care services in Uganda. UDHS 2006. Available from: URL: docs.mak.ac.ug/sites/ default/files/Amnah\%20Grand.doc

14. Kalpalata A Bhaisare, et al. Utilization of postnatal care services in tribal area of Maharashtra 1487 International Journal of Medical Science and Public Health | 2014 | Vol 3 | Issue 12

15. Nigeria Demographic and Health Survey (2008).National Population Commission and ICF

16. Koblinsky, M., Anwar, I., Mridha, M.K., Chowdhury, M.E., Botlero, R. (2008) Reducing Maternal Mortality and Improving Maternal Health: Bangladesh and MDG 5 J Health Popul Nutr. 26(3): 280-294

17. SumefunDolapoOluwaseyi DETERMINANTS OF POSTNATAL CARE NONUTILIZATION AMONG WOMEN IN NIGERIA Student Number: 681554 University of Witwatersrand, Johannesburg, February 2014

18. Hove et al., 1999).[ref-Hove, I., Siziya, S., Katilo, C. \&Tshimanga, M. (1999). Prevalence and associated factors for non-utilisation of postnatal care services: Population-based study in KuwadzanaPeri-urban area, Zvimba district of Mashonaland West Province,

19. Tukur Dahiru, Oche Mansur Oche. Determinants of antenatal care, institutional delivery and postnatal care services utilization in Nigeria, The Pan African Medical Journal. 2015;21:321. doi:10.11604/ pamj. 2015.21.321.6527 Available online at: http://www.panafrican-medjournal.com/content/article/21/321/

20. Muchabaiwa, L., Mazambani, D., Chigusiwa, L., Bindu, S., Mudavanhu, V. (2012). Determinants of maternal healthcare utilization in Zimbabwe. International Journal of Economic Sciences and Applied Research, 5(2), 145162

21. Goldman N, Pebley AR. Childhood immunization and pregnancy related services in Guatemala. Health Transit Rev. 1994;4:29-44.

22. Yinager G, Workineh D, Aregawi $H$ (2013) Factors affecting utilization of postnatal care service in Jabitena district, Amhara region, Ethiopia.Science Journal of Public Health 2: 169-176. 